\title{
Urinary Incontinence in the Elderly
}

Part 3 of a Series of Articles on Incontinence

Mark Goepel, Ruth Kirschner-Hermanns, Annette Welz-Barth, Klaus-Christian Steinwachs, Herbert Rübben

\section{SUMMARY}

Background: Urinary incontinence is a common and distressing complaint in the elderly. Its causes include structural changes in vesical muscle as well as impaired neural control and age-related changes of the lower urinary tract. Incontinence can also be a side effect of medication.

Methods: The PubMed database was selectively searched for publications containing the terms "urinary incontinence" and "elderly." Studies with a high level of evidence were chosen as the main basis for this review.

Results: The individualized diagnostic evaluation of the incontinent elderly patient should generally be non-invasive. The evaluation may reveal urinary incontinence of several different types: stress incontinence, overactive bladder, and mixed incontinence. The treatment generally involves medication, such as anti-muscarinic agents, alpha-receptor blockers, and/or serotonin/noradrenalin reuptake inhibitors, combined with modifications of personal behavior, such as bladder training, altered fluid intake, and pelvic floor contraction. A number of minimally invasive surgical techniques can be useful for patients in operable condition, whenever such an operation seems reasonable in view of the patient's overall situation.

Conclusion: Urinary incontinence in the elderly can be readily evaluated, and the currently available forms of treatment often bring satisfactory relief with an economical use of medical resources and with little or no additional discomfort for the patient.

Gite this as: Dtsch Arztebl Int 2010; 107(30): 531-6 DOl: 10.3238/arztebl.2010.0531

Klinik für Urologie und Kinderurologie, Klinikum Niederberg Velbert: Prof. Dr. med. Goepel

Urologische Klinik, Universitätsklinikum Aachen: PD Dr. med. Kirschner-Hermanns

Klinik für Geriatrische Rehabilitation, Kliniken St. Antonius Wuppertal: PD Dr. med. Welz-Barth

Neuropsychiatrische Praxis, Nürnberg:

PD Dr. med. Steinwachs

Urologische Klinik, Universitätsklinikum Essen:

Prof. Dr. med. Dr. h. c. Rübben
U rinary incontinence in the elderly is becoming an increasing medical and socioeconomic problem. The reasons are demographic trends and an increase in the number of patients with chronic diseases such as diabetes, Parkinson's disease, and dementias (such as Alzheimer's disease). People affected by urinary incontinence carry a vast psychological burden, and the demands on those around them constitute a social problem as well as a care problem. Of the people living with urinary incontinence who require treatment or care in Germany, more than 2 million are older than 60 years (11\% of this age group), in those older than 80 , almost $30 \%$ are affected (1). In adults, the estimated prevalence of urinary tract symptoms is $17 \%$, and in people older than 80 , more than $75 \%$ (2).

In old age, almost as many men as women are affected by urinary urge symptoms ("overactive bladder”, OAB). Urge incontinence vitally affects people's quality of life (and can result, for example, in depression, falls, skin complications, social isolation, hospital admissions, or admissions to nursing homes) and people's mortality (3). Recent insights, especially into central bladder control and into the storage and micturition function of the bladder create a rather more complex picture of incontinence in the elderly, compared with only a few years ago. People with impaired bladder function who are up to 65 years old usually have functional defects of the bladder, bladder outlet, or pelvic floor, whereas the capacity to remain continent in old age is mainly influenced by changed neurogenic control and weakening compensatory mechanisms (4).

This review article is based, on the one hand, on the specialty experiences of the different authors and, on the other hand, on a structured literature search of the PubMed database, using the search terms "urinary incontinence" and "elderly".

In this article, we provide an overview of the frequency, causes, types, investigative techniques, and treatment strategies for urinary incontinence in the elderly.

\section{Pathogenesis \\ Overactive bladder}

An overactive bladder is common in elderly people and is characterized by the symptoms of immediate urinary urgency, pollakisuria, and, in case of involuntary urinary loss, also by urge incontinence. The presumed 


\section{BOX 1}

Non-invasive diagnostic evaluation in elderly people with urinary incontinence

- Medical history

- Physical examination

- Rapid urine testing

- Drinking and micturition diary (if possible for 2 days and 2 nights)

- Pad weighing test

- Measurement of residual urine

\section{BOX 2}

\section{Further diagnostic evaluation in elderly people with urinary incontinence}

- Uroflowmetry

- Ultrasonography of the urinary tract

- Perineal and introitus ultrasonography

- Urethrocystoscopy

- Gynecological examination and calibration of the urethra

- Urodynamic examination

- Micturition-cysto-urethrogram (MCU) or urodynamic examination by video

causes for such impaired bladder function include involuntary detrusor contractions that are mediated by the muscarinic receptors, which can be urodynamically confirmed even during the filling phase. Structural changes to the bladder with a loss of detrusor elasticity are caused by collagenic restructuring (5-8). The detrusor muscle undergoes an aging process of its own.

\section{Stress incontinence}

Stress incontinence results from an insufficient sphincter mechanism at the bladder outlet. The diagnosis is confirmed by involuntary urinary loss as a result of a passive increase in intravesical pressure owing to physical stimuli such as coughing, sneezing, or crunching the abdominal muscles in the absence of detrusor contractions on urodynamic testing.

In everyday clinical practice, symptoms of urge and stress incontinence are often observed as a combination-so-called mixed incontinence.

\section{Diabetes}

Diabetes is associated with an increased risk of developing urinary incontinence. The prevalence of diabetes has risen in recent years. In the industrialized world, almost $25 \%$ of people older than 75 are now affected (9). The risk increases in tandem with the number of years a patient has had diabetes, and the risk of severe incontinence symptoms is almost twice as high as in subjects without type 2 diabetes (10). Urodynamic investigations in elderly people with type 2 diabetes have shown pathological findings in $79 \%$ of men and $59 \%$ of women (reduced sensory reflexes, detrusor hypercontractibility, residual urine, increased bladder capacity) (11). In addition to the central and peripheral polyneuropathic changes, different diabetes-related functional impairments take effect in the development of urinary incontinence:

- Changed sensory reflex owing to polyneuropathy

- Reduced mobility owing to diabetic foot

- Impaired vision owing to diabetic retinopathy

- Changes to fluid intake owing to diabetogenic nephropathy.

\section{Diagnostic evaluation}

In most elderly people with incontinence, non-invasive diagnostic evaluation can be used to reach a diagnosis if an underlying functional impairment is suspected, and conservative therapeutic approaches can be deployed. On the basis of a detailed medical history, a fluid intake and micturition diary that is kept for two days (if possible accompanied by weighing tests for the incontinence pads), clinical examination, urine (rapid test) diagnostic evaluation, and measuring of residual urine after intentional micturition, possibly impaired bladder function can be assessed. The extent of the primary examination should be adapted to the individual patient's requirements and needs.

If the described diagnostic evaluation does not enable a conclusive assessment of the situation, or if conservative treatment has failed, more extensive diagnostic tests should be conducted as long as this is tolerable for the patient and as long as a positive therapeutic approach is expected. Uroflowmetry with subsequent measuring of residual urine allows conclusions about the underlying malfunction. Perineal sonographic and endoscopic examinations of the lower urinary tract and a gynecological examination in women constitute the next step on the diagnostic ladder. Urodynamic examination is always required if it might influence the patient's treatment, if primary treatment has remained unsuccessful, or if a surgical procedure is planned (Box 1, 2).

\section{Therapeutic options}

\section{Pelvic floor exercises, bladder management}

Physical measures and behavioral interventions are important in elderly patients, in addition to medication treatment that takes into account risks and side effects.

A Cochrane Review of 13 randomized studies including 714 women investigated the value of pelvic 
floor exercises versus placebo in women with stress incontinence. The probability of regaining continence was increased 17-fold in the group doing the exercises, a statistically significant increase (12) (evidence level $1 \mathrm{~A})$.

Bladder management includes micturition and toilet training as well as pelvic floor exercises. Toilet training and pelvic floor training are of particular importance in incontinence in the elderly. These therapeutic measures need to be individually tailored, however, taking into account patients' mobility, motivation, and cognitive competence. The greatest successes have been achieved by means of professional care and therapeutic instruction. A combination of drug therapy and behavioral therapy should always be considered. Active measures such as functional pelvic floor exercises are supported by passive treatments, such as electrotherapy. Cognitive approaches in the sense of a conditioning of behaviors and delaying strategies further complement the therapeutic approach. Relaxation techniques can also help reduce urinary urgency.

Magnetic stimulation treatment can be a useful addition to pelvic floor exercises as well as bladder training in elderly patients.

\section{Medication treatment}

Changes to the acetylcholine metabolism pose a therapeutic obstacle to medication treatment for the overactive bladder in elderly patients. Central cholinergic transmitter systems connect the cerebral cortex as an information store with the hippocampus (the primary region for learning and memory storage) (13). Comparing age dependent muscarinic receptor binding in the brain between the bilateral frontal cortex and the cerebellum has shown an age dependent decrease of about 8\% per decade (14). Patients with Alzheimer's disease and other dementias, Parkinson's disease, type 2 diabetes in adults, multiple sclerosis, and chronic alcoholism are at an age independent increased risk for cognitive impairments.

\section{Anticholinergics}

In Germany different anticholinergic drugs are available to treat urge incontinence or symptoms of urinary urgency, whose selectivity profiles are partly different. In vitro data have shown that propiverine, tolterodine, fesoterodine, and trospium chloride all have a clear affinity for all muscarinic receptor types. Darifenacin and solifenacin are relatively selective for M3 receptors. All available substances are significantly effective against the main symptoms of an overactive bladder and urge incontinence (evidence level 1A).

The decisive element in terms of neurological side effects, apart from passing the blood-brain barrier, is the relative affinity of anticholinergics for the M1 receptor, while blocking the M3 receptors in the smooth detrusor muscles is a vital prerequisite for clinical effectiveness.

The specific effect of the different anticholinergic substances on elderly patients' cognitive functioning

\section{FIGURE 1}
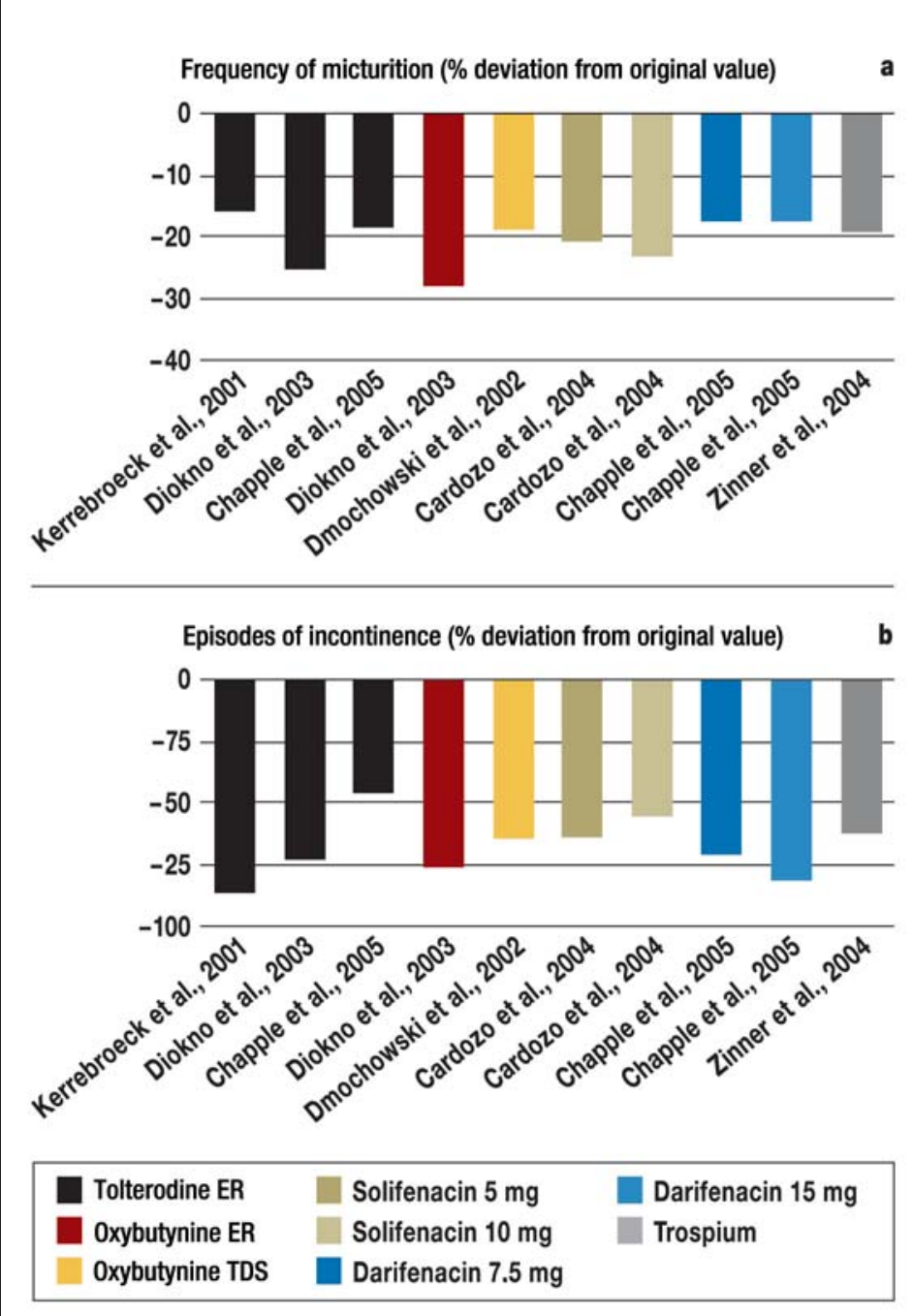

Main effects of licensed anticholinergic substances, shown by respective licensing study a) Frequency of micturition,

b) Frequency of incontinence episodes.

From: Goepel M, Steinwachs KC: Wie beeinflussen Medikamente zur Therapie der Harninkontinenz die Gehirnfunktion beim älteren Menschen, Der Urologe A 2007; 46 (4): 387-92. With permission from Springer.

$\mathrm{ER}=$ extended release; TDS $=$ transdermal delivery system

has been investigated for some substances. Parameters such as word recognition and memory were investigated, as were general reaction times. The end points relating to cognitive functioning for darifenacin and placebo did not reach significance (16) (evidence level 2A). The results of a comparative study pitting darifenacin against extended release oxybutynine showed similar results (17) (evidence level 2A). Similarly, the tests used showed no measurable changes for tolterodine when extended release tolterodine was compared with extended release oxybutynine (18) (evidence level 2A). For trospium chloride, studies have compared the substance with oxybutynine $20 \mathrm{mg}$ by 
FIGURE 2
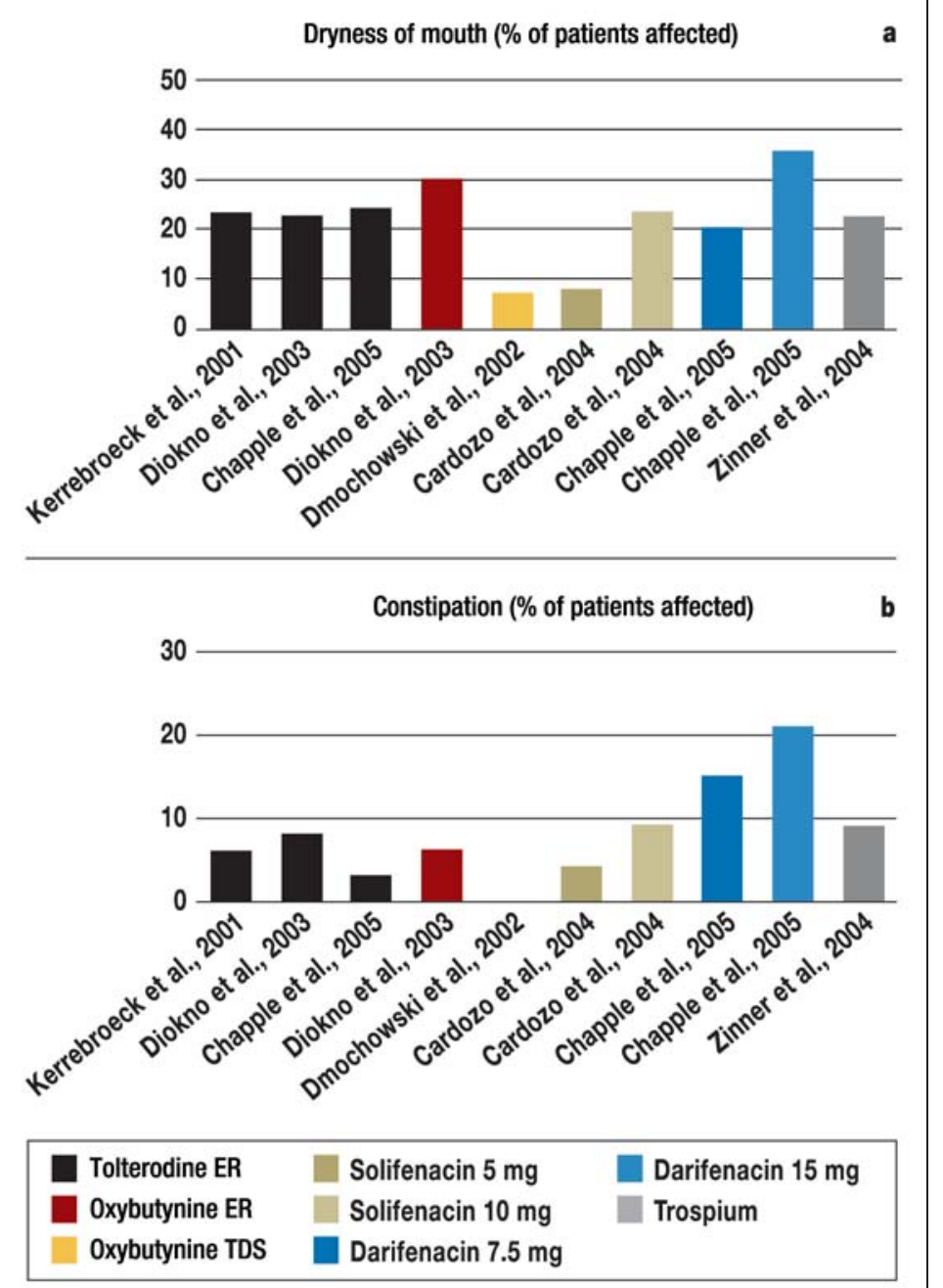

Prevalence of urinary tract symp-

toms in the general population relative

to people's age, modified from (2)

\section{FIGURE 3}

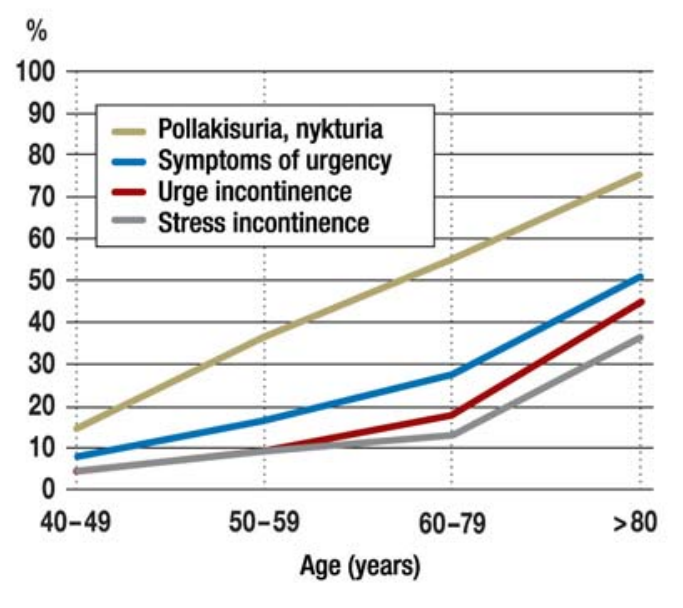

Side effects of licensed anticholinergic substances, shown by respective licensing study a) Dryness of mouth,

b) Constipation.

From: Goepel M, Steinwachs KC: Wie beeinflussen Medikamente zur Therapie der Harninkontinenz die Gehirnfunktion beim älteren Menschen, Der Urologe A 2007; 46 (4): 387-92. With permission from Springer.

$\mathrm{ER}=$ extended release; TDS = transdermal delivery system

means of the multichannel electroencephalogram (EEG). No significant changes to the EEG were found after administration of trospium chloride (19) (evidence level 2B) (Figures 1, 2, 3) (Box 3).

\section{Comedications with anticholinergic or adverse effects}

The typical elderly patient with urinary incontinence is often also receiving medication for other comorbidities. For this reason, before treatment for urge incontinence or symptoms of urinary urgency is taken up, the medication that the patient is already receiving should be reviewed for anticholinergic side effects and the planned treatment for urge incontinence adjusted if necessary (Box 4, adapted from [20]). Commonly prescribed pharmaceuticals with anticholinergic effects include furosemide/frusemide, digoxin, theophylline, nifedipine, prednisolone, and cimetidine (Box 4).

\section{Duloxetine}

Duloxetine has been licensed for the drug treatment of stress incontinence in women. The efficacy and tolerability of duloxetine in stress incontinence was documented in 4 randomized, placebo controlled, double blind, phase 2 and phase 3 studies that included more than 1900 patients (21) (evidence level 2A). Daily intake of duloxetine $2 \times 40 \mathrm{mg}$ lowered the number of episodes of incontinence significantly, by more than $50 \%$. The mechanism of action is based on stimulation of motor neurons of the pudendal nerve, which originate in the sacral Onuf's nucleus. Duloxetine strengthens sphincter contractility without impairing the coordinated function of bladder and urethra. The main side effect was nausea, which affected some $25 \%$ of patients in the study. Stepping up the dosage over time is intended to counteract the nausea. In elderly patients, duloxetine is rarely prescribed. Although duloxetine has regularly shown efficacy in incontinence after prostatectomy in men, a relevant licensing study is currently lacking.

\section{Surgical treatment}

An indication for surgery exists in elderly people with an incompetent vesical sphincter if they are generally able to have surgery and if conservative therapeutic measures have failed. 


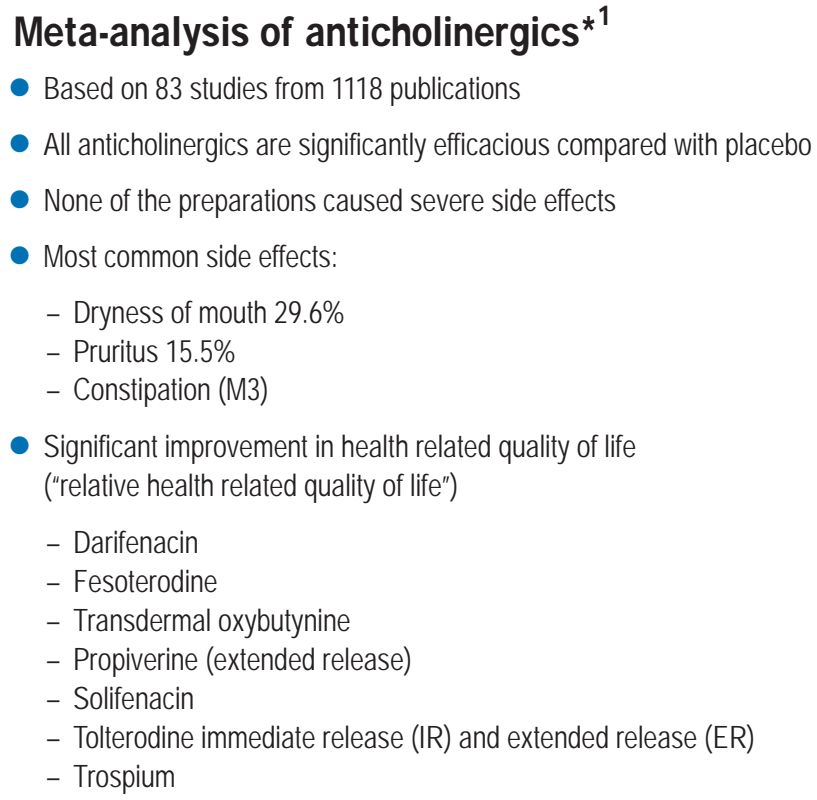

- Significant improvement in health related quality of life ("relative health related quality of life")

- Darifenacin

- Fesoterodine

- Transdermal oxybutynine

- Propiverine (extended release)

- Solifenacin

- Tolterodine immediate release (IR) and extended release (ER)

- Trospium

${ }^{1}$ Modified from (15)
Commonly prescribed anticholinergic substances $*^{*}$

- Anticholinergics

- Antiemetics/antivertigo drugs

- Anti-Parkinson

- Spasmolytics (gastrointestinal tract)

- Spasmolytics (urogenital tract)

- Migraine medication

- Bronchodilators

- Preanesthetics

- Mydriatic drugs

- Medications with anticholinergic side effects

- Antiarrhythmic agents

- Antidiarrheal drugs

- Antihistamines

- Muscle relaxants

- Medication for ulcers

- Antidepressants

- Antipsychotic drugs

- Herbal preparations

$\star^{1}$ modified from (20)

\section{Prostate treatment}

Transurethral resection of the prostate (TURP) is a safe and successful intervention to reduce symptoms of urinary incontinence in patients with age-related benign prostatic enlargement (BPE) and lower urinary tract symptoms (LUTS), in whom drug treatment has not been sufficiently effective (alpha-receptor blockers, antimuscarinic drugs, 5-alpha reductase inhibitors). Numerous minimally invasive alternative techniques are at the surgeon's disposal, which also bring about a significant reduction in symptoms (transurethral microwave thermotherapy [TUMT], transurethral needle ablation [TUNA], laser approaches). The choice of surgical methods in individual elderly patients, and the decision whether the treatment of last resort should be urine drainage techniques (permanent catheter, intraprostatic stents) depends on the general condition of the patient and his comorbidities.

\section{Depot injections}

In elderly female patients, periurethral collagen injections have been studied. 10 months postoperatively, $83 \%$ of patients were still cured of their symptoms, but afterwards the success rate dropped rapidly to $20 \%$ in parallel to the increasing time interval since the procedure. Further, de-novo detrusor instabilities affected $40 \%$ of patients (21) (evidence level 3).

\section{Open or laparoscopic colposuspension}

In some $60 \%$ of elderly female patients, colposuspension can safely be recommended on the basis of their general condition. $75 \%$ of patients were cured (22) (evidence level 3). Laparoscopic approaches have become equally effective as open procedures but impose less of a burden on the patient.

\section{Sling suspension of the urethra (TVT/TOT)}

The tension free vaginal tape (TVT) described by Ulmsten and the resulting developments such as transobturator tape (TOT) are minimally invasive therapeutic approaches in women with stress incontinence and can be used in elderly patients. Long-term results of the TVT method over 11 years have shown a persistent continence rate of more than $80 \%$; this method is thus equal to open Burch colposuspension (23) (evidence level 2A). Complications are rare (TVT, bladder perforation; TOT, pain in the thigh).

\section{Conclusion}

Urinary incontinence as a symptom of impaired bladder function is common in elderly people and poses a heavy burden on patients and their social environment. Non-invasive diagnostic evaluation can provide initial pointers as to which treatment may be indicated. Severe cases and those that are refractory to treatment will have to be examined invasively if a stringent approach is taken. Surgical intervention in elderly patients will have to be considered if a patient's general condition is such that they can tolerate surgery, if a patient has stress incontinence or mixed incontinence with a high proportion of stress incontinence, and if conservative therapeutic approaches have reduced symptoms to an insufficient extent. The treatment of the symptomatic overactive bladder in elderly patients consists of 
administering anticholinergics. The available substances differ with regard to their affinity for the muscarinic receptors M1 to M5 in terms of their pharmacokinetic and pharmacodynamic properties, but they are comparable with regard to their main effects and primary side effect profile. If a relevant comorbidity is present or the patient is simultaneously taking other drugs with anticholinergic effects, however, substances without or with very slight central side effects should be preferred.

Conflict of interest statement

The authors declare that no conflict of interest exists according to the guidelines of the International Committee of Medical Journal Editors.

Manuscript received on 23 December 2008, revised version accepted on 2 November 2009

Translated from the original German by Dr Birte Twisselmann.

\section{REFERENCES}

1. Weltz-Barth A: Inkontinenz im Alter, ein soziales und ökonomisches Problem, Urologe 2007; 46: 363-4.

2. Goepel M, Hoffmann JA, Piro M, Rübben H, Michel MC. Prevalence and physician awareness of symptoms of urinary bladder dysfunction. Eur Urol 2002; 41: 234-9

3. Füsgen I, Melchior H: Inkontinenzmanual. Berlin-Heidelberg-New York: Springer 1997, 55.

4. Griffith D, Derbyshire S, Stenger A, Resnick N: Brain Control of normal and overactive bladder. J Urol 2005: 1862-7.

5. Elbadawi A, Yalla SV, Resnick NM: a) Structural basis of geriatric voiding dysfunction. I. J Urol 1993; 150: 1650-6.

6. Elbadawi A, Yalla SV, Resnick NM: b) Structural basis of geriatric voiding dysfunction. II. J Urol 1993; 150: 1657-67.

7. Elbadawi A, Yalla SV, Resnick NM: c) Structural basis of geriatric voiding dysfunction. III. J Urol 1993; 150: 1668-80.

8. Elbadawi A, Yalla SV, Resnick NM: d) Structural basis of geriatric voiding dysfunction. IV. J Urol 1993; 150: 1681-95.

9. Wernecke J, Dreyer M: Patienten mit Diabetes mellitus im Altenpflegeheim. Eur J Geriatr 2003; 5: 123-7.

10. Lifford KL, Curham GC, Hu FR, Barbieri RL, Grodstein F: Type 2 diabetes mellitus and risk of developing urinary incontinence. J Am Geriatr Soc 2005; 53: 1851-7.

11. Kebapci N, Yenilmez A, Efe B, Entok E, Demirustu C: Bladder dysfunction in type 2 diabetic patients. Neurourol Urodyn 2005; 26: 814-9.
12. Dumoulin C, Hay-Smith J: Pelvic floor muscle training versus no treatment for urinary incontinence in women. A Cochrane systematic review. Eur J PhysRehabil Med 2008; 44: 47.

13. Andersson KE: Antimuscarinics for treatment of overactive bladder, Lancet Neurology 2004: 46-53.

14. Norburya R, Travisa MJ, Erlandssonb K, Waddingtonb W, Owensc J, Ellb PJ,Murphya DG: SPET imaging of central muscarinic receptors with $(\mathrm{R}, \mathrm{R})[123 \mid]-\mid-Q N B:$ Methodological considerations. Nucl Med Biol 2004; 31: 583-90.

15. Chapple CR, KhullarV, Gabriel Z, Muston D, Bitoun CE, Weinstein Dl: The effects of antimuscarinic treatments in overactive bladder, an update of a systematic review and metaanalysis, Eur Urol 2008; 54 543-62.

16. Lipton RB, Kolondner K Wesnes K: Assessment ot cognitiv function of the elderly population: effects of darifenacine. J Urol 2005; 173: 493-8.

17. Kay G, Crook T, Rekeda L, Lima R, Ebinger U, Arguinzoniz M, Steel M: Differential effects on the antimuscarinic agents Darifenacin and Oxybutynin ER on memory in older subjects. Eur Urol 2006; 50: 317-26.

18. Kay G, Kardiasmenos K, Crook T: Differential effects of the antimuscarinic agents tolterodine tartrate ER and oxybutynine chloride ER on recent memory in older subjects. Neurourol Urodyn 2006; 25: 615, Abstract 87.

19. Pietzko A, Dimpfel W, Schwantes U, Topfmeier P: Influences of trospium chloride and oxybutynin on quantitative EEG in healthy volunteers. Eur J Clin Pharmacol 1994; 47: 337-43.

20. Mintzer J, Burns A: Anticholinergic side-effcts of drugs in elderly people. J Royal Soc Med 2000; 93: 457-62.

21. Norton PA, Zinner NR, Yalcin I, Bump RC: Duloxetine vs. Placebo in the treatment of stress urinary incontinence. Am J Obstet Gynecol 2002; 187: 40-8.

22. Tan E, Tekkis PP, Cornish J, Teoh TG, Darzi AW, Khullar V: Laparoscopic versus open colposuspension for urodynamic stress incontinence. Neurourol Urodyn 2007; 26: 158-69.

23. Nilsson CG, Palva K, Rezapour M, et al.: Eleven years prospective follow-up of the tension free vaginal tape procedure for treatment of stress urinary incontinence. Int Urogynecol J Pelvic Floor Dysfunct 2008: 19: 1043.

\section{Corresponding author}

Prof. Dr. med. Mark Goepel

Urologie, Klinikum Niederberg

Robert-Koch-Str. 2

42549 Velbert

goepel@klinikum-niederberg.de 